Original Research Article

\title{
Knowledge, attitude and prescriptional practice about fixed dose combinations among medical practitioners in tertiary care hospital
}

\author{
Aravind Ravichandran ${ }^{1 *}$, Jayapriya Balamurugan ${ }^{2}$, Shankareswari $^{3}$, Ramalingam Sekar $^{4}$
}

\begin{abstract}
${ }^{1}$ MBBS Student, Government Theni Medical College, Theni, Tamil Nadu, India

${ }^{2}$ Department of Pharmacology, Thoothukudi Medical College, Thoothukudi, India

${ }^{3}$ Department of Pharmacology, Government Theni Medical College, Theni, Tamil Nadu, India

${ }^{4}$ Department of Microbiology, Government Theni Medical College, Theni, Tamil Nadu, India
\end{abstract}

Received: 23 April 2017

Revised: 28 June 2017

Accepted: 29 June 2017

*Correspondence to:

Aravind Ravichandran,

Email: aravind95@ outlook.com

Copyright: (C) the author(s), publisher and licensee Medip Academy. This is an openaccess article distributed under the terms of the Creative Commons Attribution NonCommercial License, which permits unrestricted noncommercial use, distribution, and reproduction in any medium, provided the original work is properly cited.

\begin{abstract}
Background: Fixed dose combination (FDC) are currently most prescribed and misused drug forms. Although fixed dose combinations are clinically better than single dosage forms, improper prescription and large amounts of irrational FDC flooding leads to unwanted financial burden and increased resistance. Therefore a study was carried out to know about the existing scenario about Knowledge Attitude and Practice of Fixed dose combinations among the resident doctors and devise some suggestions for improving the rationality. The objective of the study was to evaluate the knowledge, attitude and prescriptional practice regarding fixed dose combinations among resident doctors working in a Government Theni medical college, Theni.
\end{abstract}

Methods: A cross-sectional descriptive study involving 100 resident doctors was conducted using a pre validated questionnaire containing 21 questions to evaluate the knowledge and prescriptional practice of Fixed Dose Combination among the study participants.

Results: Ninety-five percent of the study participants were aware of the Fixed dose combination. Increased compliance and synergistic drug effect are the commonly cited advantages, whereas difficulty in dose adjustment and increased side effects were the commonly told disadvantages. Only $13 \%$ of the participants could name a single banned drug. Antibiotics (63\%), NSAIDS (18\%) were the commonly prescribed FDCs among study participants. Internet $(58 \%)$, followed by textbook (42\%) and colleagues (37\%) were the common sources of knowledge about FDCs. Increasing awareness about Essential Medicines List (63\%), regular CME $(55 \%)$ and prior notification $(50 \%)$ are some of the measures recommended by study participants to improve the awareness.

Conclusions: Although the participants are aware of basic knowledge of fixed dose combinations are acceptable, prescribing FDC them often, many of the study participants lack knowledge about the rationality of these drugs. From our study, conducting regular CME's about new Fixed dose combinations in the medical colleges and periodic notification of FDC's are some of the suggested approaches to improve the rationality of prescription. Since Internet is listed as the most common source of knowledge about FDC, information about FDC can be sent through mails, text messages, which will play a part in improving the rationality of FDC.

Keywords: Fixed dose combinations, KAP, Prescription, Rationality

\section{INTRODUCTION}

Fixed dose combinations are a popular type of drug dosage forms in which two or more drugs in specific dose are combined and used for therapeutic purposes. The Food and drug administration, USA defines a combination product as "combination of two or more active ingredients in a fixed ratio of doses". ${ }^{1}$ Currently fixed dose combination accounts for $50-69 \%$ of the medicine prescribed around the world and every medical prescription has at least one fixed dose combination. ${ }^{2,3}$

The claims of fixed dose combinations are better patient compliance, lower cost, and synergistic action of the 
drugs. ${ }^{4}$ Yet there are unwanted side effects, financial burden and drug resistance if not properly prescribed. Absence of new drug research in developing countries like India has led to pharmaceutical companies misusing FDC as purely commercial activity and thereby producing many irrational FDCs. ${ }^{5}$ These irrational FDCs are a growing problem in the country and they not only cause harm to the patients by adding unnecessary side effects, but also causes drug resistance - surely a long term alarming problem. ${ }^{5}$

The stand of medical scientific community about FDC is critical. It claims that many of the Fixed Dose Combinations that are marketed are largely irrational and, even if it is rational, it is limited by pharmacokinetic incompatibility of the drugs. ${ }^{6}$ In a recent analysis, out of the 264 FDCs approved in India, only 54 FDCs were found to be rational and for the remaining FDCs, the safety and effectiveness remains a matter of investigation. ${ }^{7}$

To be noted, although recently in March 2016, more than 324 Fixed Dose Combinations marketed in India are banned, still many of them are commonly prescribed and available as over the counter. ${ }^{8}$

A study assessing knowledge of medical practitioners about rational fixed dose combination prescribing is needed because of the growing concern of irrational FDCs flooding the market. Knowledge about fixed dose combination is deemed necessary as the adoption of any drug lies in the hands of the prescribing doctor. Due to the above said facts, the study was done to assess the knowledge, attitude and prescription practice of fixed dose combinations among medical practitioners and interns of a government tertiary care hospital - Government Theni Medical College.

\section{METHODS}

A questionnaire based study was cross sectional with sample size of 100 .

The study was conducted among 100 participants, which included both male and female interns and medical practitioners in a tertiary care hospital. The questionnaire used for this study was designed incorporating appropriate questions regarding the knowledge, attitude and prescription aspect of fixed dose combinations.

The questionnaire was pre-validated for its accuracy, by the faculties of Department of Pharmacology, Government Theni Medical College. The questionnaire used contained in total of 21 questions consisting of both open and closed ended questions, and was given to the study participants belonging to the various departments - Medicine, Surgery, Pediatrics, Orthopedics, Psychiatry, Obstetrics and Gynecology, Pediatrics, Radiology, Neurology, Otorhinolaryngology and Ophthalmology departments.
Before the start of the study, a briefing was given about the nature of the study, explaining the reason behind and the implications of the study, and then the consent was got from the willing participants before issuing the questionnaire. The procedure for completing the questionnaire was thoroughly explained. The participants anonymously completed the questionnaire regarding their Knowledge, attitude, practice of fixed dose combinations. The researcher stayed along with the respondent till he/she finished filling up the questionnaire. The filled up questionnaire and the consent forms are collected and the questionnaire data was analyzed using Microsoft excel software.

\section{Inclusion criteria}

Inclusion Criteria used for selecting study population are:

- Medical practitioners and House surgeons in Government Theni Medical College

- Willingness to participate in the study

\section{RESULTS}

The following results were obtained at the end of the study. Among the study population $65 \%$ were males and $35 \%$ were females. Nearly all of the study participants were aware of the term Fixed Dose Combinations (96\%), whereas only $87 \%$ of the study participants had correct understanding of what Fixed Dose Combination meant.

While asking about the advantages and disadvantages of FDC, improved patient compliance $(54 \%)$, followed by increased drug effect $(50 \%)$ were the commonly mentioned advantages of FDCs (Figure 1), while difficulty in dose adjustment (74\%), increased adverse effects $(52 \%)$, followed by increased cost $(43 \%)$ are the mentioned disadvantages (Figure 2).

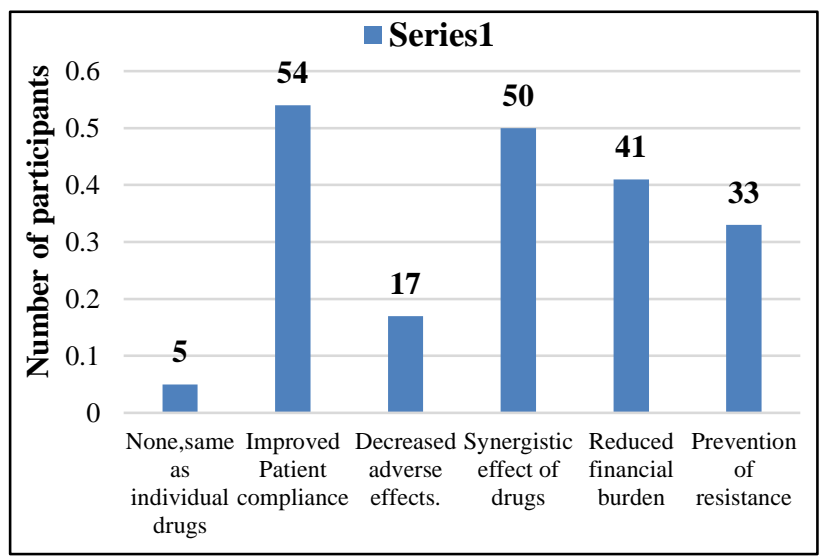

Figure 1: Advantages of fixed dose combinations.

Among the study participants, only $13 \%$ were able to list at least one Fixed dose combination that has been banned, while majority of the participants $(69 \%)$ weren't aware of 
the fixed dose combinations included in the essential list of medicines (Figure 3).

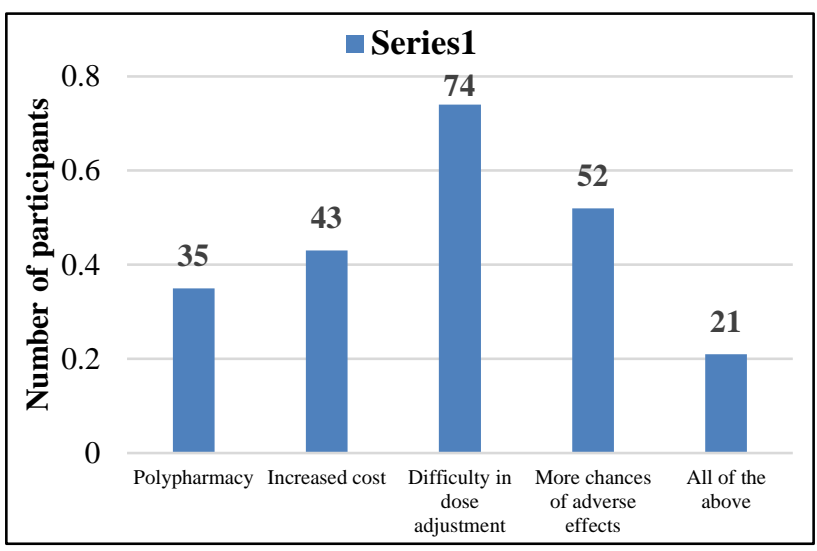

Figure 2: Disadvantages of fixed dose combination

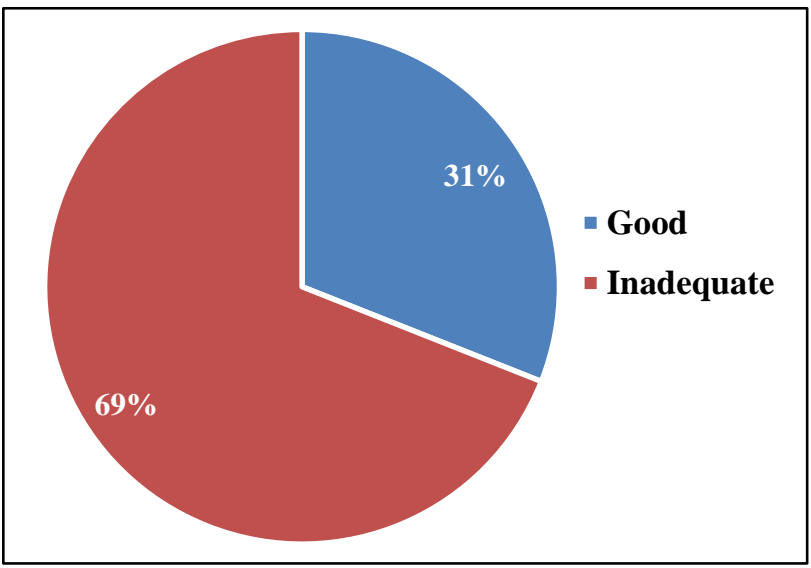

Figure 3: Knowledge about essential list of medicines.

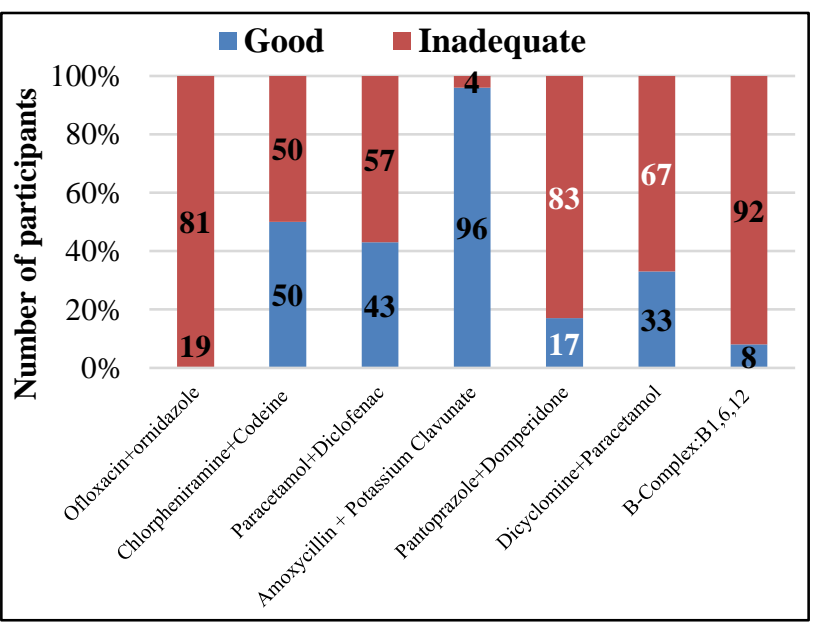

Figure 4: Knowledge of rationality of fixed dose combinations among study participants.

Antibiotics (63\%), followed by NSAIDS (18\%) are among the commonly prescribed fixed dose combinations by the study participants (Table 1). Most common clinical condition mentioned by the participants is infections (22\%) (Table 2).

Table 1: Commonly prescribed fixed dose combinations.

\begin{tabular}{|ll|}
\hline $\begin{array}{l}\text { Name of the fixed dose } \\
\text { combination }\end{array}$ & $\begin{array}{l}\text { Number of } \\
\text { participants }\end{array}$ \\
\hline Amoxicillin + Clavulanic acid & 38 \\
\hline Clotrimoxazole & 14 \\
\hline Ofloxacin + Ornidazole & 9 \\
\hline Aceclofenac + Paracetamol & 13 \\
\hline Omeprazole + Domperidone & 9 \\
\hline Amoxicillin + Cloxacillin & 2 \\
\hline Monteleukast + Levocetrizine & 4 \\
\hline Theophylline + Etophylline & 2 \\
\hline Diclofenac +Tramadol & 5 \\
\hline Tamsulosin +Dutasteride & 1 \\
\hline Glimipiride combination & 2 \\
\hline Domperidone + Ranitidine & 1 \\
\hline
\end{tabular}

Table 2: Common clinical conditions for which FDCs are prescribed.

\begin{tabular}{|l|l|}
\hline Name of the clinical condition & Number \\
\hline Bacterial infections & 22 \\
\hline Respiratory infections & 13 \\
\hline Gastritis & 5 \\
\hline Osteoarthritis & 5 \\
\hline APD & 5 \\
\hline Diabetes & 3 \\
\hline Diarrhea & 4 \\
\hline Tb & 2 \\
\hline Asthma & 4 \\
\hline Muscular Disorders & 5 \\
\hline Hypertension & 6 \\
\hline Others (Seizures, CAD, CSOM, Malaria) & 7 \\
\hline
\end{tabular}

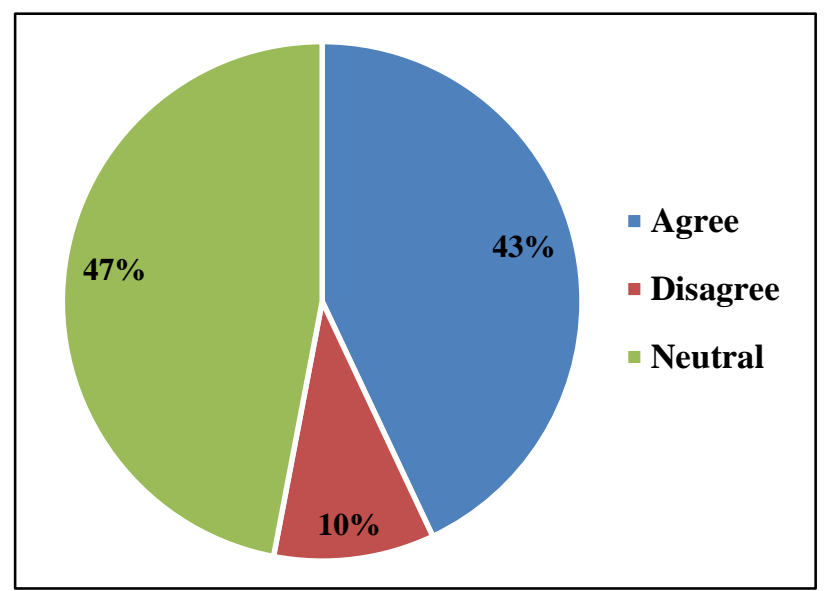

Figure 5: Attitude towards, superiority of fixed dose combination to individual drugs. 
The attitude of the physicians towards Fixed Dose Combinations are mixed - neutral response (47\%), $43 \%$ of the study population feel that FDCs are superior to the individual drugs, and $10 \%$ of the participants disagree that the FDCs are superior (Figure 5). Nearly seventy percent of the participants supported that FDC could be cost effective for the patients. Ninety two percent of the study participants agreed that there is a need for increased awareness about FDC's.

Increasing the awareness about essential drug list (63\%), regular CMEs $(55 \%)$ and prior notification of banned drugs by the institutions $(55 \%)$ were some of the suggestions agreed by the study participants to improve rationality of prescription of FDCs (Figure 6). Common sources of knowledge about FDC was from the internet $(58 \%)$, textbooks $(42 \%)$, colleagues (37\%) (Figure 7).

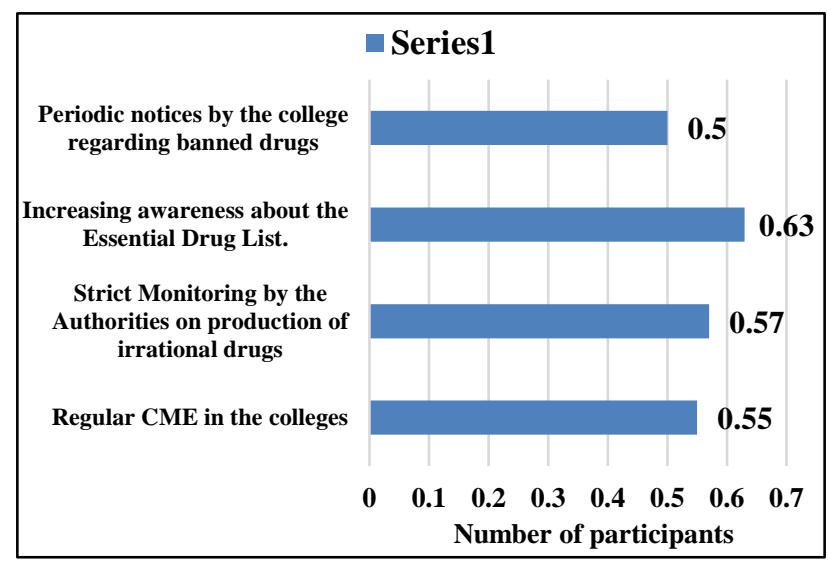

Figure 6: Suggestions to improve rationality of FDC prescription.

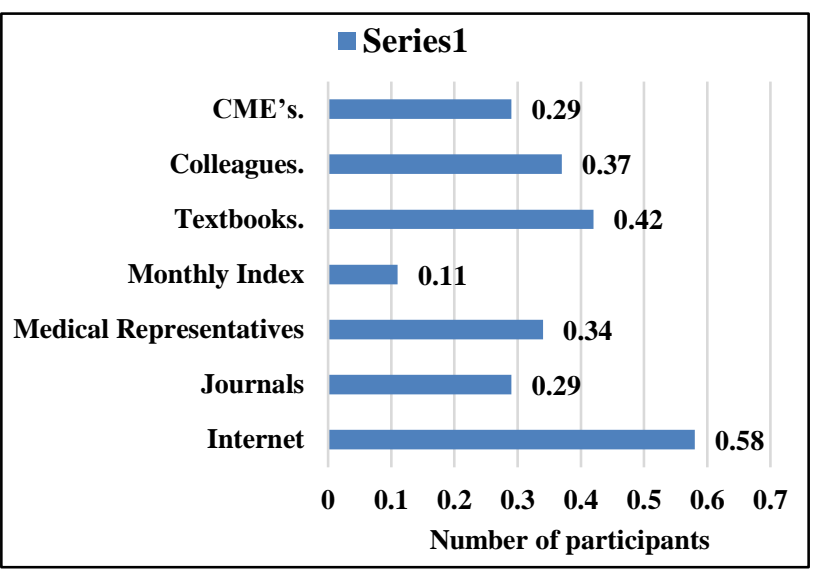

Figure 7: Sources of knowledge of fixed dose combination among study participants.

\section{DISCUSSION}

Drugs are the main sword of modern medicine in the treatment of ailments. As prescription of Medicine in India solely lays in the hands of the doctor their basic knowledge about the drugs and their proper rational prescription lays the foundation for effective treatment. The combination of Knowledge, attitude and practice determines how a treatment process succeeds.

There are number of studies to find out the rationality of FDCs, but studies to assess the medical practitioners' ability is very much limited and our study was aimed to fill that lacuna.

Goswami et al, and and Manu Get al, has done KAP of FDC study with post graduates as study participants and Beena et al, with dentists and with a lower sample size $(\mathrm{n}=30) \cdot{ }^{9-11}$

In our study, $96 \%$ of the participants were aware of the term FDC, which was higher than that of Manu $G$ et all (73.4\%). The results for the advantages of FDCs i.e., 'improved patient compliance' and 'increased drug effect', are similar to the results of Manu et all.

The most important disadvantages reported in our study are difficulty in dose adjustment, followed by increased adverse effects. Only $21 \%$ of the study participants correctly identified all the adverse effects of the FDCs. Contrastingly in Manu $\mathrm{G}$ et all participants reported drug resistance as the major disadvantage.

Essential drug list is published separately by WHO and Govt. of India and contains the basic drugs which meets the needs of the population, and should be present in a healthcare setup. Having so much importance, the knowledge about it is deemed very necessary. The lack of basic awareness about Fixed dose combination in Essential list of Medicines is $70 \%$. Goswami et.all (69\%) also yielded similar results.

The knowledge about the banned drugs were very much lacking, since only $13 \%$ of the participants were able to list at least one banned drug in India, contrastingly $42 \%$ in Manu et all and $41 \%$ in Goswami et all were able to list at least one banned drug. Knowledge about the banned drugs is very much necessary to prevent the deleterious consequences to the patients. This shows the continued prescription and also the availability of banned drugs in the market.

Regarding the rationality of some Fixed dose combinations, only $39 \%$ of the responses were adequate and many of them were unable to list the rationality behind it (Figure 4), Goswami et all also yielded similar results $(20 \%)$.

Antimicrobials (63\%), NSAIDS (18\%) are the commonly prescribed Fixed Dose Combinations in our study. Neetesh et al, Pillay A et al, Rayasam SP et al, also yielded similar results in their study. ${ }^{2,12,13}$

Quinolones + Nitroimidazoles (Ofloxacin + Ornidazole) are commonly used in the treatment of diarrhea and G.I infections. Although these combinations are neither 
recommended in any standard textbooks nor there is any proven clinical synergism of these combinations, they are currently prescribed for the diagnostic imprecision. These combinations are not only harmful to the patient, are also major contributors for the development of resistance, which is a serious concern nowadays. ${ }^{5}$ Eighty two percent of the study participants reported that Ofloxacin + Ornidazole combination is rational. This reflects the lack of knowledge regarding FDCs among the medical practioners.

Chlorpheniramine and codeine syrups are popular antitussives, since both the drugs causes sedation as a side effect, combination of them is not recommended.

Combinations of two NSAIDS like Paracetamol + Diclofenac are very popular over the counter medications for painful conditions. Pharmacologically, there is expected synergism since these acts upon the same enzymes, but combinations of same class of drugs will add up the side effects. In a recent study conducted, there are 124 FDC involving only NSAIDs in 2739 trade names marketed in India, of which only 34 are approved by Drugs Authority of India. ${ }^{14}$

The scenario about fixed dose combination differs markedly between India and other developed countries like USA where only a limited number of Fixed dose combinations are approved and marketed whereas in India thousands of FDCs are flooding the market. ${ }^{12}$

Why this huge amount of FDC in India? Are all these rational? The answer is quite disappointing, at the same time alarming. Several studies have reported that the huge amounts of FDC's have no rational basis. ${ }^{2,5,7,15,16}$ In a study done by Krunal Dalal et all, nearly $52 \%$ of the FDC approved between 2009-2014 are irrational.

The main contributing factors for this scenario can be attributed to the loopholes in the drug regulatory bodies in the country. ${ }^{5}$ Drugs controller General of India have the final authority to issue drug licenses. But most of the irrational drugs licenses are issued by the state authorities in northern states of India, who do not have the authority to do so, allowing the pharmaceutical companies to sell in other states where the license have not been granted. ${ }^{12}$ The Parliamentary report showed that the drugs were approved without necessary clinical trials and based on perceptions alone. ${ }^{17}$

Time to time notifications has been given to the manufacturers, but it has not deterred them not to come with irrational FDC. ${ }^{12}$

Absence of efficient drug reaction surveillance mechanism also is a contributing factor. Since adverse effects have been documented against the prevailing irrational FDC in small populated countries like Switzerland, but none were reported from a large country like India, denoting that the existing mechanism doesn't function well.
It is not easy to dismiss the fact that medical fraternity also contribute by falling into the traps of Pharma companies and their marketing gimmicks. ${ }^{12}$ Necessary sensitization and training could reduce the prescription of irrational FDCs, since the implementation of a drug in the treatment lies in the hands of a doctor. ${ }^{18}$

"Commercial attitude of industry, irrational prescriptions due to lack of training among physicians are the major causes for the misuse of Fixed dose combination. ${ }^{19}$

By all these discussion, it cannot be regarded that Fixed dose combination is not useful. The advantages of Fixed dose combinations are reaped only when there is an identifiable patient population, for whom treatment with particular combination of actives in the fixed ratio has been shown to be safe and effective (increased therapeutic efficacy or decreased chance of adverse effects).

It is high time that some serious action is taken either by strict monitoring of drugs or to prescribe FDC only in a justifiable case. For which a better rationality and knowledge of FDCs is necessary. If the current trend is continued to grow without any efforts taken, a sure catastrophe lies. The ultimate consequences are to be faced by the common people exposing them to unwanted side effects, burdening them with extra-cost.

From our study, conducting regular CME's about new Fixed dose combinations and periodic notification are some of the suggested approaches to improve the rationality of prescription. Since Internet is listed as the most common source of knowledge about FDC, information about FDC can be sent through mails, text messages, which will play a part in improving the rationality of FDC.

Although the participants are aware of fixed dose combinations and are prescribing them often, many of the study participants lack knowledge about the rationality of these drugs. To fulfil the lacunae, CME's, newsletters and notifications can improve the rationality of FDC prescription.

Funding: No funding sources

Conflict of interest: None declared

Ethical approval: The study was approved by the Institutional Ethics Committee

\section{REFERENCES}

1. WHO Expert Committee on Specifications for Pharmaceutical Preparations: thirty-ninth report. (WHO technical report series; 929). 2005.

2. Pillay A, Keche Y, Yegnanarayan R, Patil V, Patil G, Dangare R. Evaluation of prescribing patterns of teaching and non teaching hospitals by undergraduate medical students in Pune, India

3. Sharma K, Sharma A, Neemawat K. An audit of prescription for rational use of fixed dose drug 
combinations at a tertiary care dental setting. J Sci Innovative Res. 2014;3:491-4.

4. Tripathi, KD. Essentials of Medical Pharmacology. 6th edition. New Delhi: Jaypee Brothers, 2008.

5. Gulhati CM. Irrational fixed-dose drug combinations: a sordid story of profits before patients. Issues Med Ethics. 2003 Jan;11(5).

6. Gupta YK, Ramachandran SS. Fixed dose drug combinations: Issues and challenges in India. Indian journal of pharmacology. 2016 Jul;48(4):347.

7. Dalal K, Ganguly B, Gor A. Assessment of rationality of fixed dose combinations approved in CDSCO list. Journal of clinical and diagnostic research: JCDR. 2016 Apr;10(4):FC05.

8. The Ministry of Health and Family Welfare. List of fixed dose combinations (FDC) banned 10/3/2016. Available at: www.drrohanjshenoy.com/wpcontent/.../2016/.../FD Cs-banned-on-10-March-2016.p

9. Goswami N, Gandhi A, Patel P, Dikshit R. An evaluation of knowledge, attitude and practices about prescribing fixed dose combinations among resident doctors. Perspectives in clinical research. $2013 \mathrm{Apr}$ $1 ; 4(2): 130$.

10. Manu G, Narasimhamurthy KM, Padmanabha TS. An evaluation of knowledge, attitude and practices about prescribing fixed dose combinations among postgraduates of a rural tertiary health care teaching hospital. Int J Basic Clin Pharmacol. 2016;5:2476-80.

11. George B. Evaluation of Awareness about Fixed Dose Combination among the Practitioners in Dentistry: A Question Based Study. International Journal of Chemical and Life Sciences. 2017 Feb 10;3(5):13224.

12. Jain NK, Akarte A, Deshmukh PT, Kannojia P, Garud N, Yadav A. Rationality of fixed dose combinations: an Indian scenario. Pharma Res. 2009;1:158-68.
13. Rayasam SP, Dudhgaonkar SS, Dakhale GN, Hire RC, Deshmukh PS, Gaikwad NN. The irrational fixed dose combinations in the Indian drug market: an evaluation of prescribing pattern using WHO guidelines.

14. McGettigan P, Roderick P, Mahajan R, Kadam A, Pollock AM. Use of fixed dose combination (FDC) drugs in India: central regulatory approval and sales of FDCs containing non-steroidal anti-inflammatory drugs (NSAIDs), metformin, or psychotropic drugs. PLoS Med. 2015 May 12;12(5):e1001826.

15. Patil PJ, Patil MJ, Patil VR, Deshmukh TA, Band SS. A survey on awareness of Fixed Dose Combinations (FDCs) among patients, physicians and pharmacists at Pune and Beed (India). Indian Journal of Pharmacy Practice. 2013;6(3).

16. Gautam CS, Saha L. Fixed dose drug combinations (FDCs): rational or irrational: a view point. British journal of clinical pharmacology. 2008 May 1;65(5):795-6.

17. Diwedi P. Regulatory control on banned drug: A review article. Critical review in pharmaceutical sciences. 2012;1(3):1-2.

18. Atal S, Phadnis P, Gudsurkar G. A study to assess and increase awareness regarding fixed dose combinations among medical undergraduates at Indore and Sagar, Madhya Pradesh, India. International Journal of Basic \& Clinical Pharmacology. 2016 Dec 28;5(2):300-6.

19. Kshirsagar M, Langade D, Patil S, Patki PS. Prescribing patterns among medical practitioners in Pune, India. Bulletin of the World Health Organization. 1998;76(3):271.

Cite this article as: Ravichandran A, Balamurugan J, Shankareswari, Sekar R. Knowledge, attitude and prescriptional practice about fixed dose combinations among medical practitioners in tertiary care hospital. Int J Basic Clin Pharmacol 2017;6:1937-42. 